\title{
Micro-explosion and autoignition of composite fuel/water droplets
}

\author{
D.V. Antonov ${ }^{1}, \quad$ G.V. Kuznetsov ${ }^{1}$, P.A. Strizhak ${ }^{1}$, O. Rybdylova ${ }^{2}$, \\ S.S. Sazhin ${ }^{2 *}$ \\ ${ }^{1}$ National Research Tomsk Polytechnic University 30, Lenin Avenue, Tomsk, 634050, \\ Russia \\ ${ }^{2}$ Sir Harry Ricardo Laboratories, Advanced Engineering Centre, School of Computing, \\ Engineering and Mathematics, University of Brighton, Brighton, BN2 4GJ, UK \\ August 29, 2019
}

\begin{abstract}
The results of detailed experimental investigations of puffing, micro-explosions and autoignition of composite fuel/water droplets free falling in a high temperature air are presented. The measurements were performed for non-mixed and premixed Diesel fuel/water and rapeseed oil/water droplets. Air temperature was in the range $850-1100^{\circ} \mathrm{C}$, initial droplet radii were in the range $0.62-1.34$ $\mathrm{mm}$, and relative volume fractions of fuel (Diesel fuel or rapeseed oil) were in the range $3-97 \%$. It is shown that the time to micro-explosion decreases with increasing temperature, weakly depends on the volume fraction of fuel, and increases with increasing droplet sizes. The latter trend is shown to be consistent with the prediction of the previously developed simple model for droplet puffing/microexplosion based on the assumption that the water component forms a spherical sub-droplet located in the centre of a fuel droplet. It is shown that the autoignition delay time for composite droplets, close to the time to micro-explosion for both fuels under consideration, is almost an order of magnitude less than that for pure fuel droplets.
\end{abstract}

Key words:

Micro-explosions, puffing, Diesel fuel, rapeseed oil, water, autoignition

\footnotetext{
${ }^{*}$ Corresponding author. E-mail: S.Sazhin@brighton.ac.uk
} 


\section{Introduction}

It is well known that micro-explosions in water-in-fuel droplets, leading to rapid disintegration of these droplets, can potentially reduce nitrogen oxide particulate emission and improve engine performance [1, 2, 3, 4, (see the first paragraph in the Introduction in 5 for further details). The term 'micro-explosions' used in the literature refers to a wide range of phenomena with different underlying physics. For example, micro-explosions investigated in [6] were triggered by pockets of air formed during droplet collisions. Micro-explosions studied in [7. were produced by exothermic reactions between aluminum and a polymer and were used to prevent metal fuel particle agglomeration. Our study will be specifically focused on micro-explosions in immiscible liquids (e.g. Diesel fuel/water droplets). Following [8], a micro-explosion can be defined as the bursting of the continuous phase (i.e. Diesel fuel or rapeseed oil) by the energy of evaporation of dispersed sub-droplets (i.e. water)'. Puffing (rapid increase in the droplet volume) usually precedes micro-explosions and the two processes are often modelled together [5].

A number of teams have presented the results of experimental studies of micro-explosions. In 9] composite droplets of water and sunflower oil emulsion were used. These droplets were representative of emulsions used in applications of biofuels. Micro-explosions of composite droplets of water and various oil products were studied in [10, 11]. The authors of 8 focused their research on water-in-oil emulsion droplets. Puffing and micro-explosions of water-in-Diesel fuel emulsion droplets exposed to high temperatures were studied in [12, 13. The authors of [14 considered micro-explosions in kerosene, Diesel, gasoline, oil, turbine and automobile oil droplets with water sub-droplets within them (see [11, 12] for a more detailed overview of the earlier experimental studies).

A number of models for puffing and micro-explosions have been suggested. These models were either relatively simple [15, 16, 17] or very advanced, based on the direct numerical simulation of the processes involved [18, 19. Although 
the models suggested in [18, 19] are certainly very useful for understanding the background of the mechanisms involved in the processes of puffing/microexplosions in droplets, the applicability of these models for practical engineering applications is not obvious. Practitioners interested in these phenomena focus mainly on such characteristics as the time to puffing/micro-explosion, but not

35 on the details of the processes inside the exploding droplet. In [5] a simple model of the processes specifically focused on a crude approximation of this time was developed. This model will be used in this paper for the analysis of experimental data.

The research to be presented focuses primarily on experimental investiga40 tion of puffing and micro-explosions in free falling water-liquid fuel droplets in a hot air. This investigation is different from those presented earlier when various droplet supports were used (e.g. [8, 11]) or when high speed droplets were injected from a nozzle (e.g. [13]). In contrast to most previous studies of this phenomenon, in our case micro-explosion of droplets will be investigated 45 together with their autoignition. Some experimental results will be compared with the predictions of a simplified model for puffing/micro-explosions earlier suggested in [5].

\section{Description of experiments}

\subsection{Composition of droplets}

Three components (water, rapeseed oil and Diesel fuel) were used in our experiments. Two types of droplets were considered: non-mixed two-component (water and liquid fuel) droplets, produced during sequential preparation of the components, and premixed droplets prepared using TWEEN 85 surfactant. In the case of non-mixed two-component droplets, a single water sub-droplet was located inside the fuel droplet. In the case of premixed droplets many small water sub-droplets were distributed almost homogeneously inside the fuel droplet.

There are three reasons for our primary interest in non-mixed droplets. Firstly, premixed emulsified fuels tend to segregate after long storage; in this 
case, an interface is formed inside the droplet, and this droplet turns into a non-mixed droplet. Secondly, the presence of an interface inside a non-mixed droplet allows us to investigate all stages of the micro-explosion/autoignition process and estimate the integral characteristics. Thirdly, for the preparation of non-mixed droplets there is no need to use TWEEN 85 surfactant. The properties of the latter have a strong effect on the conditions and characteristics of

65 micro-explosions.

The combustible liquids were selected primarily due to their wide use as currently available and prospective fuels. Diesel fuel is widely used for internal combustion engines because of its reliability and efficiency. Rapeseed oil is widely used as a biofuel. Biodiesel produced from rapeseed oil is believed

70 to be ecologically clean. Typical concentrations of these combustible liquids in prospective fuels are expected to be between $90 \%$ and $100 \%$ [20, 21]. Using the results presented in numerous research papers (e.g. [8, 5, 14] and the references therein), we expect that the addition of water to fuel (Diesel fuel or rapeseed oil) will lead to the intensification of fuel droplet disintegration and autoignition of the fuel vapour/air mixture. This occurs due to rapid increase in the liquid surface area during the micro-explosions, which speeds up the evaporation process and decreases the physical ignition delay that is controlled by the breakup, heating and evaporation of droplets [22].

\subsection{Experimental setup}

80

A scheme of the setup used in our experiments is shown in Fig. 1. A muffle furnace was used to heat air in the chamber up to about $1200^{\circ} \mathrm{C}$. The distribution of the air temperature inside the furnace was recorded using low inertia thermocouples with errors of temperature measurement less than $\pm 3^{\circ} \mathrm{C}$ and errors of time measurement less than $0.1 \mathrm{~s}$. The results inferred from thermocouple measurements were collected using National Instruments Thermocouple Input Module NI 9219.

The temperature in the enclosure was measured using three thermocouples as schematically shown in Fig. 1. Typical differences in the readings from these 
thermocouples were in the range $6-9^{\circ} \mathrm{C}$; the reading from the upper thermocou-

90 was the minimal one. This gradient in temperature in the enclosure was ignored in our analysis and the temperature in the enclosure was assumed equal to the one inferred from the reading from the middle thermocouple. The temperature of the furnace was maintained in the range $800-1200^{\circ} \mathrm{C}$; the droplet radii were in the range $0.62-1.34 \mathrm{~mm}$.

The axis of the furnace was vertical which meant that contact was avoided between the free falling droplets and the inner walls (the cases when this contact took place were excluded from the analysis). The fragmentation of falling droplets was recorded using a high speed video camera, capable of operating at speeds of up to $10^{5}$ frames per second. The parent and disintegrated droplets were illuminated from below.

The experiments were performed in three stages. Firstly, a two-component droplet of the required size was formed with the help of a weigher mounted on a holder, as shown in Fig. 1. Secondly, a special device was mechanically brought into contact with the holder to release the droplet leading to its free fall in a hot air. After that, the high speed video camera mentioned above (here operating at 5400 frames per second) recorded the droplet and its fragmentation products. The droplet remained in the enclosure for less than $1 \mathrm{~s}$.

\subsection{Analysis of images}

Typical recorded images of disintegrating droplets are presented in Fig. 2. Fig. 2a shows non-mixed droplets, while Fig. 2b shows premixed droplets (emulsions). All images, including the ones in Fig. 2, were processed using Phantom Camera Control software 23. These images were used for the analysis of droplet fragmentation times.

All images were scaled using the inner diameter of the furnace $(50 \mathrm{~mm})$. Droplet diameters were scaled using the initial droplet diameters inferred from their volumes, assuming that the droplets were initially spherical. Also, the radii of the vapour bubbles $\left(R_{b}\right)$ inside droplets were inferred from the analysis 
of images. Finally the effective diameters of the aerosol clouds generated after

the micro-explosions were estimated as $D_{c}=\left(D_{1}+D_{2}\right) / 2$, where $D_{1}$ and $D_{2}$ are maximal and minimal diameters of cloud ellipsoids (see Fig. 3b). In Fig. 3b the images of the autoignition of fuel vapour/air mixture are shown alongside the images of fragmented droplets.

The number of child droplets and their sizes were calculated using the algorithm described in 24]. Then the total area of child droplets was calculated and compared with the initial area of the parent droplet. This allowed us to estimate the change in the total area of the liquid surface during micro-explosions.

Altogether, more than 1000 experiments were performed, and about 460 images showing micro-explosions and the following autoignition were obtained.

130 Those images for which the droplet transit time inside the furnace was not sufficient to collect the integral characteristics of micro-explosions and estimate the number and sizes of droplet fragments after micro-explosion were not used in our analysis. This approach allowed us to gather reliable statistics for the experimental results in identical conditions.

\section{Results}

\subsection{Times to micro-explosion}

The plots of the observed times to micro-explosion versus the air temperature for droplets with volume fractions of water $10 \%$ and volume fractions of Diesel or rapeseed oil of $90 \%$ are shown in Fig. 4. In all cases, the droplet radii were $0.84 \mathrm{~mm}$ (which corresponds to volume $2.5 \mu \mathrm{l}$ ). Air temperature varied between $850^{\circ} \mathrm{C}$ and $1100^{\circ} \mathrm{C}$. The reason for selecting this range of temperatures was that at temperatures less than $850^{\circ} \mathrm{C}$ micro-explosions were not observed, while at temperatures greater than $1100^{\circ} \mathrm{C}$ the time to micro-explosion was too short to perform measurements (sometimes micro-explosions took place before the droplets were released).

As can be seen in Fig. 4, the time to micro-explosion decreases with increasing air temperature for both droplets, and this decrease is nonlinear. When 
air temperature increased from $850^{\circ} \mathrm{C}$ to $1100^{\circ} \mathrm{C}$, this time decreased by $55 \%$ for water/Diesel fuel droplets and only by $14 \%$ for rapeseed oil/water droplets. The reason for the difference in the behaviour of these droplets is not clear to us. The trend for the time to micro-explosion to decrease with increasing air temperature is related to an exponential decrease in the evaporation time of both droplet components with temperature.

The plots of the observed time to micro-explosion versus the volume fraction cases the initial droplet radii were $0.84 \mathrm{~mm}$, but air temperatures varied from one experiment to another. The images of parent and child droplets at various stages of puffing and micro-explosion are shown in Figs. 6b-6f.

The dynamics of a non-mixed droplet with volume fractions of water $10 \%$ and Diesel fuel $90 \%$ are shown in Fig. 6b. Air temperature in this case was $950^{\circ} \mathrm{C}$. Three stages of the dynamics of the parent droplet can be clearly seen 
in this figure. The slow growth of droplet diameter during Stage I could be attributed to thermal swelling and the slow growth of vapour bubbles. The evaporation at this stage is expected to be weak. At Stage II, approximately $0.35 \mathrm{~s}$ after droplet release, the droplet diameter increases rapidly showing the development of the puffing process which can be clearly seen on the droplet image taken during this period. This puffing is followed by a rapid development of the micro-explosion and formation of many child droplets during Stage III.

The dynamics of a droplet similar to the one shown in Fig. $6 \mathrm{~b}$ but for a volume fraction of water $10 \%$ and of rapeseed oil $90 \%$ are shown in Fig. 6c. In this case we can see not three but four stages in the development of the process. Initially, during Stage I, droplet diameter remains almost constant which shows the balance between swelling and evaporation processes. After this initial stage, a slow growth in the droplet can be seen during the remaining part of Stage I, as shown in Fig. 6b. The droplet dynamics in the following stage (Stage II) look rather different. In Fig. 6c we can clearly see a reduction, rather than growth, in droplet size. This is attributed to droplet breakup leading to a detachment of small sub-droplets from the droplet surface as illustrated by the images taken at approximately $0.35 \mathrm{~s}$ and $0.45 \mathrm{~s}$. Stages III and IV show the rapid growth of droplets and their micro-explosion as in the cases of Stages II and III shown in Fig. 6b.

The dynamics of a droplet similar to the one shown in Fig. $6 \mathrm{~b}$ but with volume fractions of water $97 \%$ and Diesel fuel 3\% are shown in Fig. 6d. In this case, during Stage I, the droplet diameter remains almost constant which indicates the balance between droplet swelling and evaporation, as shown in Fig. 6c. At Stage II, a slow growth in droplet diameter, attributed to the formation of a vapour bubble, can be seen. This growth is followed by a rapid decrease in the droplet diameter until it reaches approximately 0.6 of the droplet initial diameter, which is attributed to bubble release leading to droplet fragmentation (not micro-explosion). Then we see another increase in the droplet diameter, attributed to the growth of another bubble, followed by a decrease in the diameter associated with the development of a micro-explosion. 
The dynamics of a premixed (emulsion) droplet with a volume fraction of fraction of water $10 \%$ and of Diesel fuel $90 \%$ (Fig. 7a) and volume fraction of water $10 \%$ and of rapeseed oil $90 \%$ (Fig. $7 \mathrm{~b}$ ) were studied. Air temperature was $1100^{\circ} \mathrm{C}$ in the case shown in Fig. $7 \mathrm{a}$ and $980^{\circ} \mathrm{C}$ in the case shown in Fig. $7 \mathrm{~b}$. In both cases the initial droplet radii were $0.84 \mathrm{~mm}$. As one can see from this pared with that for the parent droplet. In both cases shown in Fig. 7 this area continued to grow after the time instant when a micro-explosion took place.

The time evolutions of the bubble radii for non-mixed droplets with a volume fraction of water $10 \%$ and of rapeseed oil $90 \%$, and volume fraction of water ${ }_{235} 97 \%$ and of rapeseed oil 3\% are shown in Fig. 8. Air temperature in the first case was $850^{\circ} \mathrm{C}$, while in the second case it was $980^{\circ} \mathrm{C}$. In both cases, the initial droplet radii were $0.84 \mathrm{~mm}$. As can be seen from this figure, bubbles formed and collapsed during very short time periods in both cases. In the case of water rich droplets, bubble formation and collapse took place later than in the case 

droplets as these droplets are not transparent. The presence of these bubbles in the droplets, however, can be inferred from the results and images shown in Fig. 6f.

\subsection{Micro-explosion and autoignition} nied by autoignition of the fuel vapour mixture. Since the total autoignition delay time is commonly considered to be the sum of the physical and chemical delay times [22], the micro-explosions, strongly affecting the physical delay, are expected to have a strong influence on this time. Hence, the importance of studying both processes together. This is done in the current section.

In our experiments, the autoignition of the fuel vapour/air mixture in the presence of child droplets and aerosol clouds was observed both in air flow and during contact of these child droplets and clouds with the inner furnace walls. At the same time, autoignition was not observed during the contact of parent droplets with these walls. In the latter case droplet rapid fragmentation was typically observed. In all cases, autoignition was seen only at temperatures greater than $950^{\circ} \mathrm{C}$. It was observed that micro-explosions typically triggered autoignition in the whole domain, while puffing led to local autoignition. For flows with premixed droplets, autoignition was not observed.

Typical images showing the development of micro-explosions and autoignition of aerosol clouds, formed as a result of the micro-explosion of a droplet with a volume fraction of water $10 \%$ and of Diesel fuel $90 \%$, are shown in Fig. 9. The droplet radius was $0.84 \mathrm{~mm}$, while the air temperature was $1100^{\circ} \mathrm{C}$. As one can see from this figure, the spread of the aerosol cloud follows the micro-explosion rather quickly $(1.7 \mathrm{~ms}$ in the case shown in Fig. 9). Then after about $0.5 \mathrm{~ms}$ the first signs of autoignition can be clearly seen. During the following $3.2 \mathrm{~ms}$ the flame spreads over a large region around the droplet.

Using images similar to those shown in Fig. 9 the autoignition delay times for composite droplets were obtained. These were compared with the autoignition 
delay times for pure Diesel fuel and pure rapeseed oil droplets. In the latter cases we could not use the setup shown in Fig. 1 as the droplet transfer time was much less than the autoignition delay time. Instead, the experimental methodology described in 25] was used. In this methodology, a furnace similar to the one shown in Fig. 1 was used, but the axis of this furnace was not vertical but horizontal. A droplet of liquid fuel was placed in the centre of the furnace on a tiny holder of diameter $0.62 \mathrm{~mm}$. This holder was introduced into the furnace with the help of a special mechanism. Video recording of the autoignition process was performed with the help of a high-speed video camera.

The plots of time to micro-explosion and autoignition delay times for Diesel fuel based and rapeseed oil based droplets versus air temperature are shown in Fig. 10. The following droplets were considered: droplets with a volume fraction of water 10\% and of Diesel fuel $90 \%$ and pure Diesel fuel droplets (Fig. 10a), and droplets with a volume fraction of water $10 \%$ and of rapeseed oil $90 \%$ and pure rapeseed oil droplets (Fig. 10b). The initial droplet radii in all cases were $0.84 \mathrm{~mm}$.

As follows from Fig. 10a, the autoignition delay for both Diesel fuel and Diesel fuel/water droplets decreases with temperature, but the autoignition delay of Diesel fuel/water droplets is almost an order of magnitude shorter than that of pure Diesel fuel droplets. Moreover, the autoignition delay time for Diesel fuel/water droplets turned out to be almost the same as the time to micro-explosion for these droplets. This is an expected result as the total autoignition delay is equal to the sum of the physical and chemical autoignition delays. The former is reduced dramatically as a result of the micro-explosion. The chemical ignition delay for Diesel fuel is expected to be very small (a fraction of a millisecond, see [22]).

Essentially the same trends as shown in Fig. 10a can be seen in Fig. 10b for rapeseed oil and rapeseed oil/water droplets. The main differences between these two cases are: 1) the autoignition delay times for rapeseed oil and rapeseed oil/water droplets are longer than those for Diesel fuel and Diesel fuel/water droplets; 2) the difference between the autoignition delay times and the time to 
micro-explosion is visibly larger for rapeseed oil/water than for Diesel fuel/water droplets. This might be attributed to the different thermophysical properties of the two fuels and different chemical ignition delays, although this problem has not been investigated so far to the best of our knowledge.

\section{Modelling of the phenomena}

As mentioned in the Introduction, the most advanced models of puffing and micro-explosion processes were suggested and developed in [18, 19]. These models were based on the Direct Numerical Simulation of the processes involved with tracking the interfaces between water and fuel, water and water vapour, water vapour and fuel, and fuel and air. The main difficulty with the application of these models to the analysis of the experimental data, described earlier, is that they require the identification of the exact initial position of the water sub-droplet in the fuel droplet. In the case of a supported droplet this could be done using the methodology described in [14. Unfortunately, it would be very difficult to do this in our experiments with free falling droplets.

Among simplified models of the phenomenon we can single out the model described in [16]. This model is focused on the late stage of the development of puffing/micro-explosion when water inside fuel droplets has evaporated and the problem reduces to the interaction between water vapour and the surrounding liquid fuel shell. The stability analysis of the system was performed assuming that this fuel shell is initially spherical. This allowed the author to predict the number and average diameter of the droplets, generated as a results of the shell rupture, as a function of the initial thickness of the shell. Thus, this model could potentially predict typical sizes of the droplets generated during microexplosions but not the times to puffing/micro-explosions.

One of the predictions of the model, which could be potentially compared with experimental data, is that the most probable diameter of the child droplets is approximately equal to 0.27 of the initial thickness of the fuel shell surrounding water vapour. We cannot infer the value of this thickness from our experiments, 
but we can anticipate that it is proportional to the original thickness of this shell surrounding water. Considering the case when water in the composite droplet occupies $10 \%$ of the overall volume of the droplet and remembering the key assumption of the model described in [16] that the water sub-droplet is spherical and is located in the centre of a spherical composite droplet, the radius of the water sub-droplet can be estimated as:

$$
R_{w}=0.1^{1 / 3} R_{d}
$$

This allows us to estimate the original thickness of the fuel shell as

$$
\delta_{f s}=R_{d}-R_{w}=\left(1-0.1^{1 / 3}\right) R_{d} \approx 0.536 R_{d}
$$

The plots of the observed numbers of child droplets $N_{\text {droplet }}$ versus the radii of the child droplets for 3 droplets, $5 \mu \mathrm{l}, 10 \mu \mathrm{l}$ and $15 \mu \mathrm{l}$, are shown in Figure 11. These droplet volumes correspond to droplet radii $1.06 \pm 0.05 \mathrm{~mm}, 1.33 \pm 0.05$ $\mathrm{mm}$ and $1.53 \pm 0.05 \mathrm{~mm}$, respectively. In all cases, ambient gas temperature was $400^{\circ} \mathrm{C}$ and water occupied $10 \%$ of the overall volume of the droplets.

In all three cases in this figure one can see clear maxima for $N_{\text {droplet }}$ at certain values of the radii of child droplets $R_{c d}$. These maxima were observed at $R_{c d}=0.095 \mathrm{~mm}, R_{c d}=0.095 \mathrm{~mm}$ and $R_{c d}=0.085 \mathrm{~mm}$ for droplets with volumes $5 \mu \mathrm{l}, 10 \mu \mathrm{l}$ and $15 \mu \mathrm{l}$, respectively. This indicates no visible increase in ${ }_{335} \delta_{f s}$ with $R_{d}$, in contrast to the prediction of Equation (1).

There are several factors which might contribute to this discrepancy between the prediction of the model suggested by [16] and experimental data. The most obvious is the key assumption of this model that the water sub-droplet is spherical and is located in the centre of a spherical composite droplet. This assumption is not compatible with our observations.

Similarly to the model described in [16], a more recent model described in [5] is also based on the assumption that the fuel shell is spherically symmetric. In contrast to [16], the authors of [5] assumed that liquid water (not water vapour) is surrounded by the fuel shell. The focus of the model described in [5] is on 345 the heating of both water and the fuel shell which makes it complementary to 
the model described in [16].

One of the main advantages of the model developed in [5] is that it is able to give a crude prediction of the time to micro-explosion, which is an easily measurable parameter. This model is based on an application of the analytical perature $20^{\circ} \mathrm{C}$ were used in the modelling. Two types of composite non-mixed droplets were considered: 1) droplets with a volume fraction of water $10 \%$ and of Diesel fuel $90 \% ; 2$ ) droplets with a volume fraction of water $10 \%$ and of rapeseed oil $90 \%$. The droplet surface temperature was taken equal to $477 \mathrm{~K}$ 375 (boiling temperature of rapeseed oil) for droplets with rapeseed oil, and three values of droplet surface temperature $(489.47 \mathrm{~K}, 513 \mathrm{~K}$ and $620 \mathrm{~K})$ were used 


\begin{tabular}{ll} 
Table 1: Rapeseed oil thermophysical properties and approximations. \\
\hline Parameter & Value $\left(T\right.$ is in $\left.{ }^{\circ} \mathrm{C}\right)$ \\
\hline Boiling temperature $\left[{ }^{\circ} \mathrm{C}\right]$ & 204 \\
Density $\left[\mathrm{kg} / \mathrm{m}^{3}\right]$ & $-0.689 T+921.72$ \\
Specific heat capacity $\left[\mathrm{J} /\left(\mathrm{kg}{ }^{\circ} \mathrm{C}\right)\right]$ & $1.9 T+1962$ \\
Thermal conductivity $\left[\mathrm{W} /\left(\mathrm{m}^{\circ} \mathrm{C}\right)\right]$ & $0.0003 T+0.1736$ \\
\hline
\end{tabular}

for modelling droplets with Diesel fuel. $513 \mathrm{~K}$ is the boiling temperature of n-dodecane.

The experimentally observed times to micro-explosion, and those predicted by the model for both types of droplets for a range of initial droplet radii 0.6 $\mathrm{mm}$ to $1.4 \mathrm{~mm}$ are compared in Fig. 12. As can be seen from this figure, for small droplets with initial radii close to $0.6 \mathrm{~mm}$ the predictions of the model for both types of droplets are close to the experimental results. For larger droplets, however, we can see clear deviations between the model predictions and experimental data, although the predicted increase in this time with increase in droplet radii is compatible with the observed increase in this time. Also the order of magnitude of the predicted and observed times is similar. The modelled results for droplets containing rapeseed oil lie between those for droplets containing Diesel fuel with boiling temperatures of $489.47 \mathrm{~K}$ and $513 \mathrm{~K}$.

The deviation between modelling and experimental results did not surprise us. The model is essentially based on the assumption that the water sub-droplet is located in the centre of the fuel droplet as in the case of the model descibed in [16. At the same time our observations show that bubbles preceding microexplosions develop away from the centre of the droplets, especially for larger droplets (cf. the images shown in Fig. 6). In this case, we would expect that the temperature at the surface of a water sub-droplet would reach the boiling point of water more quickly than predicted by the original model described in [5]. This is compatible with the results shown in Fig. 12.

To summarise, we can conclude that the model developed in [5] can predict 
tally, and correct orders of magnitude for the values of this time. For relatively small droplets (with initial radii close to $0.6 \mathrm{~mm}$ ) the values of the time to microexplosion predicted by the model and observed experimentally are reasonably close.

some correct trends regarding the time to micro-explosion observed experimen-

To the best of our knowledge, the modelling of the total autoignition delay is always based on the assumption that it can be estimated as a sum of physical and chemical autoignition delays. The physical autoignition delay takes into account droplet breakup, heating and evaporation, followed by the diffusion and convection of fuel vapour into air. The chemical autoignition is controlled by chemical reactions leading to explosion of the fuel vapour/air mixture. In the case of the experiments described in the previous section the physical autoignition delay is controlled mainly by the time to micro-explosion.

The rigorous modelling of chemical autoignition, even for a single hydrocarbon, would need to take into account hundreds of species and thousands of chemical reactions. For example, the comprehensive kinetic mechanism for autoignition of cyclohexane comprises 499 species and 2323 reactions [27]. The authors of 27] managed to replace this with a reduced mechanism, comprising 50 species involved in 143 reactions. Even this reduction, however, would not have solved the problem of modelling the autoignition of realistic Diesel fuels comprising more than a hundred components [28]. An alternative approach to modelling the autoignition of Diesel fuel is based on the application of the Shell model [29, 30]. The adaptation of this model to modelling the autoignition of rapeseed oil has not been investigated to the best of our knowledge. Even simpler models of Diesel spray autoignition based on a single Arrhenius-type chemical reaction have been used in many papers, including [31].

In the case of Diesel fuel, the application of the Shell model was justified by the fact that the chemical autoignition delay for this fuel is generally much shorter than the physical autignition delay and this is confirmed by the results shown in our Fig. 10. Using the latter figure we can take one step further and ignore the contribution of chemical autoignition delay altogether. This delay is 
expected to be comparable to the errors in the estimate of the time to microexplosion.

\section{Conclusions}

Micro-explosion is shown to be the dominant mechanism of disintegration the start of of disintegration via puffing of premixed droplets decreased by 1.11.5 times. Time to puffing for these droplets decreased by 1.6-1.8 times when the air temperature increased from $800^{\circ} \mathrm{C}$ to $1000^{\circ} \mathrm{C}$. The times to micro-explosion of these droplets decreased by 1.1.-1.4 times when the air temperature was infrom $3 \%$ to $97 \%$, the time to micro-explosion of premixed droplets decreased by $5-15 \%$.

It was shown that the autoignition delay time for composite Diesel fuel/water droplets is almost the same as the time to micro-explosion of these droplets. fuel droplets in similar conditions. The autoignition delay time for composite rapeseed oil/water droplets was shown to be slightly longer than the time to micro-explosion of these droplets. This time was seen to be almost an order of magnitude less than the autoignition delay time of pure rapeseed oil droplets in 455

The observed increase in the time to micro-explosion of composite droplets of increasing droplet size is shown to be consistent with the prediction of the previously developed model for droplet puffing/micro-explosion based on the assumption that the water component forms a spherical sub-droplet located in 
the centre of the fuel droplet. Actual values of this time were shown to be noticeably shorter than predicted by the model except for those of relatively small droplets with initial radii close to $0.6 \mathrm{~mm}$.

\section{Acknowledgements}

Work on this paper was supported by the National Research Tomsk Polytech465 nic University (project VIU-ISHFVP-60/2019) (contributions by D.V. Antonov, G.V. Kuznetsov, P.A. Strizhak), and the EPSRC, UK (Grant Nos. EP/R012024/1 and EP/M002608/1) (contributions by O. Rybdylova and S.S. Sazhin).

\section{References}

口[1] A. M. Ithnin, H. Noge, H. A. Kadir, W. Jazair, An overview of utilizing water-in-diesel emulsion fuel in diesel engine and its potential research study, Journal of the Energy Institute 87 (4) (2014) 273 - 288. doi:https://doi.org/10.1016/j.joei.2014.04.002. URL http://www.sciencedirect.com/science/article/pii/ S1743967114200717

${ }_{475}^{4}[2]$ O. A. Elsanusi, M. M. Roy, M. S. Sidhu, Experimental investigation on

a a diesel engine fueled by diesel-biodiesel blends and their emulsions at various engine operating conditions, Applied Energy 203 (2017) 582 - 593. doi:https://doi.org/10.1016/j.apenergy.2017.06.052

1] URL http://www.sciencedirect.com/science/article/pii/ $480 \quad$ S0306261917308000

[3] J. K. Mwangi, W.-J. Lee, Y.-C. Chang, C.-Y. Chen, L.-C. Wang, a An overview: Energy saving and pollution reduction by using green fuel blends in diesel engines, Applied Energy 159 (2015) 214 - 236. doi:https://doi.org/10.1016/j.apenergy.2015.08.084 
URL http://www.sciencedirect.com/science/article/pii/ S030626191501020X

[ [4] B. K. Debnath, U. K. Saha, N. Sahoo, A comprehensive review on the application of emulsions as an alternative fuel for diesel engines Renewable and Sustainable Energy Reviews 42 (2015) 196 - 211. doi:https://doi.org/10.1016/j.rser.2014.10.023. URL http://www.sciencedirect.com/science/article/pii/ S1364032114008405

[5] S. S. Sazhin, O. Rybdylova, C. Crua, M. Heikal, M. A. Ismael, Z. Nissar, A. R. B. Aziz, A simple model for puffing/microexplosions in water-fuel emulsion droplets, International Journal of Heat and Mass Transfer 131 (2019) 815 - 821. doi:https: //doi.org/10.1016/j.ijheatmasstransfer.2018.11.065 URL http://www.sciencedirect.com/science/article/pii/ S0017931018338936

${ }_{500}^{6}$ [6] C. H. Wang, W. G. Hung, S. Y. Fu, W. C. Huang, C. K. Law, On the burning and microexplosion of collision-generated two-component droplets: miscible fuels, Combustion and Flame 134 (2003) 289-300.

[7] M. A. Rubio, I. E. Gunduz, L. J. Groven, T. R. Sippel, C. W. q Han, R. R. Unocic, V. Ortalan, S. F. Son, Microexplosions and 505 \ ignition dynamics in engineered aluminum/polymer fuel parti1 cles, Combustion and Flame 176 (2017) 162 - 171 doi:https: //doi.org/10.1016/j.combustflame.2016.10.008.

a URL http://www.sciencedirect.com/science/article/pii/ S0010218016303078

510 [ [8] O. Moussa, D. Tarlet, P. Massoli, J. Bellettre, Parametric study of the micro-explosion occurrence of w/o emulsions, International q Journal of Thermal Sciences 133 (2018) 90 - 97. doi:https: //doi.org/10.1016/j.ijthermalsci.2018.07.016. 


URL http://www.sciencedirect.com/science/article/pii/
S1290072917317970
[9] D. Tarlet, E. Mura, C. Josset, J. Bellettre, C. Allouis, P. Massoli,
Distribution of thermal energy of child-droplets issued from an optimal
micro-explosion, International Journal of Heat and Mass Transfer 77 (2014)
1043 - 1054. doi:https://doi.org/10.1016/j.ijheatmasstransfer.
2014.06.054
URL http://www.sciencedirect.com/science/article/pii/
S0017931014005262

[10] P. A. Strizhak, M. V. Piskunov, R. S. Volkov, J. C. Legros, Evaporation,

1. boiling and explosive breakup of oil - water emulsion drops under intense

${ }_{525}$ radiant heating, Chemical Engineering Research and Design 127 (2017) 72

- 80. doi:https://doi.org/10.1016/j.cherd.2017.09.008

a URL http://www.sciencedirect.com/science/article/pii/ S0263876217304616

[11] D. Antonov, J. Bellettre, D. Tarlet, P. Massoli, O. Vysokomornaya, ${ }_{530}$ 口 M. Piskunov, Impact of holder materials on the heating and explosive 1 breakup of two-component droplets Energies 11 (12) (2018) 3307. doi: $10.3390 /$ en 11123307

URL https ://www .mdpi .com/1996-1073/11/12/3307

[12] M. Y. Khan, Z. A. A. Karim, A. R. A. Aziz, M. R. Heikal, C. Crua, Puffing 535 a and microexplosion behavior of water in pure diesel emulsion droplets during leidenfrost effect, Combustion Science and Technology 189 (7) (2017) 1186-1197. arXiv:https://doi.org/10.1080/00102202.2016.1275593, doi:10.1080/00102202.2016.1275593.

URL https://doi.org/10.1080/00102202.2016.1275593

540 [13] M. A. Ismael, M. R. Heikal, A. R. A. Aziz, C. Crua, M. El-Adawy, Z. Nissar, a M. B. Baharom, E. Z. Zainal A., Firmansyah, Investigation of puffing and micro-explosion of water-in-diesel emulsion spray using shadow imaging, 
Energies 11 (9) (2018) 2281. doi:10.3390/en11092281.

URL https : //www .mdpi .com/1996-1073/11/9/2281

545 [14] D. Antonov, R. Volkov, P. Strizhak, An explosive disintegration of heated fuel droplets with adding water, Chemical Engineering Research and Design 140 (2018) 292 - 307. doi:https: //doi.org/10.1016/j.cherd.2018.10.031. URL http://www.sciencedirect.com/science/article/pii/ S0263876218305616

[15] H. Watanabe, Y. Matsushita, H. Aoki, T. Miura, Numerical sima ulation of emulsified fuel spray combustion with puffing and micro-explosion, Combustion and Flame 157 (5) (2010) 839 - 852. doi:https://doi.org/10.1016/j.combustflame.2010.01.013.

555 uRL http://www.sciencedirect.com/science/article/pii/ S0010218010000246

[16] O. G. Girin, Dynamics of emulsified fuel drop micro-explosions, Atomization and Sprays 27 (5) (2017) 407-422.

[17] Y. Zhang, Y. Huang, R. Huang, S. Huang, Y. Ma, S. Xu, $560 \quad \square$ Z. Wang, A new puffing model for a droplet of butanol-hexadecane blends, Applied Thermal Engineering 133 (2018) 633 - 644. doi:https://doi.org/10.1016/j.applthermaleng.2018.01.096

a URL http://www.sciencedirect.com/science/article/pii/ S1359431117330405

565 [18] J. Shinjo, J. Xia, L. C. Ganippa, A. Megaritis, Physics of puffing and microexplosion of emulsion fuel droplets, Physics of Fluids 26 (10) (2014)

a 103302. arXiv:https://doi.org/10.1063/1.4897918 doi:10.1063/1. 4897918

URL https://doi.org/10.1063/1.4897918

570 [19] J. Shinjo, J. Xia, Combustion characteristics of a single decane/ethanol 


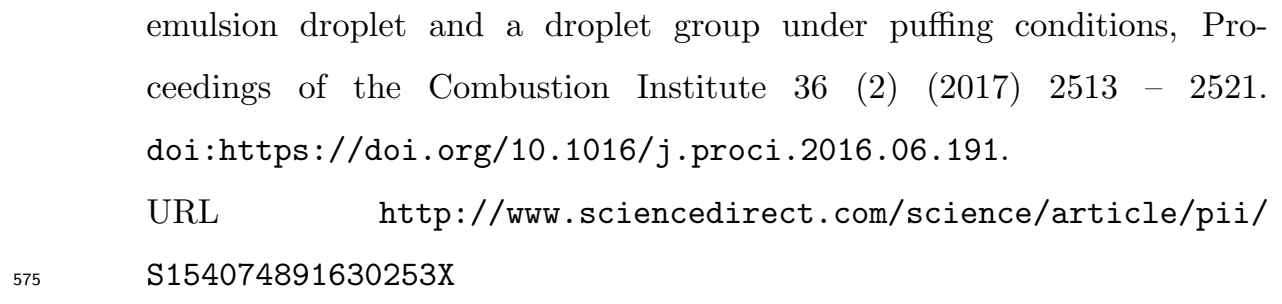

[20] T. Kadota, H. Yamasaki, Recent advances in the combustion of water fuel emulsion, Progress in Energy and Combustion Science 28 (5) (2002) 385404.

[21] H. Watanabe, T. Harada, Y. Matsushita, H. Aoki, T. Miura, The characteristics of puffing of the carbonated emulsified fuel, International Journal of Heat and Mass Transfer 52 (2009) 3676-3684.

[22] E. M. Sazhina, S. S. Sazhin, M. R. Heikal, V. I. Babushok, R. J. R. Johns, A detailed modelling of the spray ignition process in diesel engines, Combustion Science and Technology 160 (1) (2000) 317-344.

[23] https://www.phantomhighspeed.com/resourcesandsupport/phantomresources/pccsoftware.

[24] D. Antonov, O. Vysokomornaya, M. Piskunov, N. Shlegel, Analysis of statistical data on drop collisions in an aerosol flow during experiments, EPJ Web Conf. 196 (2019) 00013. doi:10.1051/epjconf/201919600013. URL https://doi.org/10.1051/epjconf/201919600013 boiling and explosive breakup of oilwater emulsion drops under intense radiant heating, Chemical Engineering Research and Design 127 (2017) 72 - 80. doi:https://doi.org/10.1016/j.cherd.2017.09.008. URL http://www.sciencedirect.com/science/article/pii/ S0263876217304616

[26] B. E. Poling, J. M. Prausnitz, J. O'Connell, The Properties of Gases and Liquids, McGraw-Hill, New York, 5th edition, 2001. 
[27] J. Griffiths, R. Piazzesi, E. M. Sazhina, S. S. Sazhin, P. A. Glaude, M. R. Heikal, CFD modelling of cyclohexane auto-ignition in an RCM, Fuel 96 (2012) 192-203.

[28] S. S. Sazhin, Modelling of fuel droplet heating and evaporation: Recent results and unsolved problems, Fuel 196 (2017) 69 - 101. doi:http://dx.doi.org/10.1016/j.fuel.2017.01.048 URL http://ww.sciencedirect.com/science/article/pii/ S0016236117300583

[29] S. S. Sazhin, E. M. Sazhina, M. R. Heikal, C. Marooney, S. V. Mikhalovsky, The Shell autoignition model: a new mathematical formulation, Combustion and Flame 117 (1999) 529-540.

[30] E. M. Sazhina, S. S. Sazhin, M. R. Heikal, The Shell autoignition model: application to gasoline and Diesel fuels, Fuel 78 (1999) 389-401.

[31] S. S. Sazhin, E. Shchepakina, V. Sobolev, Order reduction in models of spray ignition and combustion, Combustion and Flame 187 (2018) 122 128. doi:https://doi.org/10.1016/j.combustflame.2017.08.025. URL http://www.sciencedirect.com/science/article/pii/ S001021801730322X 


\section{Figure Captions}

Fig. 1 A schematic presentation of the setup used in the experiments.

620 of droplets and autoignition of the fuel vapour/air mixture: (a) a non-mixed droplet with a volume faction of water 10\% and of rapeseed oil 90\%; (b) a nonmixed droplet with a volume fraction of water $10 \%$ and of Diesel fuel $90 \%$; in both cases the initial droplet radii were $0.84 \mathrm{~mm}$ and air temperature was $980^{\circ} \mathrm{C}$.

625

Fig. 3 Typical video images showing our approach to calculation of key parameters characterising the micro-explosion process: (a) cross-sectional area of the furnace; (b) dynamics of bubble growth inside a non-mixed droplet during the puffing process (the volume fraction of water $10 \%$ and volume fraction of for free falling droplets with initial radii $0.84 \mathrm{~mm}$. The solid curve refers to a non-mixed droplet with a volume fraction of water $10 \%$ and of rapeseed oil $90 \%$, while the dashed curve refers to a non-mixed droplet with a volume fraction of water $10 \%$ and of Diesel fuel $90 \%$. In both cases error bars are shown.

640

Fig. 5 Average observed times to micro-explosion versus volume fraction of fuel for free falling droplets with initial radii $0.84 \mathrm{~mm}$ and air temperature $950^{\circ} \mathrm{C}$. The solid curve refers to water/rapeseed oil droplets while the dashed curve refers to water/Diesel fuel droplets. In both cases error bars are shown. 
Fig. 6 (a) Time evolution of normalised diameters squared for the processes shown in Figs. 6b-6f (letters near the curves refer to the figure where the details of the process are shown; the initial droplet radii in all cases were $0.84 \mathrm{~mm}$ ); (b) a non-mixed droplet with a volume fraction of water 10\% and of Diesel fuel $90 \%$ in air with temperature $950^{\circ} \mathrm{C}$; (c) a non-mixed droplet with a volume fraction of water $10 \%$ and of rapeseed oil $90 \%$ in air with temperature $950^{\circ} \mathrm{C}$; (d) a non-mixed droplet with a volume fraction of water $97 \%$ and of rapeseed oil $3 \%$ in air with temperature $950^{\circ} \mathrm{C}$; (e) a premixed droplet with a volume fraction of water $10 \%$ and of rapeseed oil $90 \%$ in air with temperature $1050^{\circ} \mathrm{C}$; (f) a premixed droplet with a volume fraction of water $10 \%$ and of Diesel fuel $90 \%$ in air with temperature $1000^{\circ} \mathrm{C}$. Various stages of the processes are described in the paper.

Fig. 7 Time evolution of the area of the liquid/air interface (droplets or 660 aerosol clouds) during a non-mixed droplet micro-explosion: (a) a droplet with a volume fraction of water $10 \%$ and of Diesel fuel $90 \%$ in air with temperature $1100^{\circ} \mathrm{C}$; (b) a droplet with a volume fraction of water $10 \%$ and of rapeseed oil $90 \%$ in air with temperature $980^{\circ} \mathrm{C}$; in both cases the initial droplet radii were $0.84 \mathrm{~mm}$. Inserts show the dependence of the normalised areas on the air temperature.

Fig. 8 Time evolution of bubble radii during a non-mixed droplet puffing/microexplosion: (a) a droplet with a volume fraction of water $10 \%$ and of rapeseed oil $90 \%$ in air with temperature $850^{\circ} \mathrm{C}$; (b) a droplet with a volume fraction of water $97 \%$ and of rapeseed oil $3 \%$ in air with temperature $980^{\circ} \mathrm{C}$; in both cases the initial droplet radii were $0.84 \mathrm{~mm}$.

Fig. 9 Typical video images showing the autoignition process of a non-mixed droplet with a volume fraction of water $10 \%$ and of Diesel fuel $90 \%$ in air with 675 temperature $1100^{\circ} \mathrm{C}$; the initial droplet radius was $0.84 \mathrm{~mm}$. 
Fig. 10 Autoignition delay times versus air temperature for pure fuel droplets (filled triangles) and non-mixed droplets with a volume fraction of water $10 \%$ and of fuel $90 \%$ (filled circles); times to micro-explosions of non-mixed droplets with a volume fraction of water $10 \%$ and of fuel $90 \%$ (filled squares). Plots (a) and (b) refer to the cases when the fuels were Diesel fuel and rapeseed oil, respectively. In both cases the initial droplet radii were $0.84 \mathrm{~mm}$.

Fig. 11 The distributions of the number of child droplets by their radii $\left(R_{c d}\right)$ for three initial volumes of droplets, $5 \mu \mathrm{l}, 10 \mu \mathrm{l}$ and $15 \mu \mathrm{l}$, for a mixture of 90 vol\% Diesel fuel and 10 vol\% water. Ambient gas temperature was $400^{\circ} \mathrm{C}$. Vertical bars show the values of $R_{c d}$ at which the number of droplets was measured and the errors of these measurements.

Fig. 12 The plots of the time to micro-explosion inferred from experimental data for droplets with a volume fraction of water $10 \%$ and of Diesel fuel $90 \%$ (triangles), and for droplets with a volume fraction of water $10 \%$ and of rapeseed oil $90 \%$ (squares). Average values of this time for droplets with Diesel fuel (rapeseed oil) points are connected with solid (dashed) lines. Predictions of the model for droplets with a volume fraction of water $10 \%$ and of Diesel fuel $90 \%$, and for surface temperatures $489.47 \mathrm{~K}, 513 \mathrm{~K}$, and $620 \mathrm{~K}$ are shown by filled circles, circles, and filled diamonds, respectively. Predictions of the model for droplets with a volume fraction of water $10 \%$ and of rapeseed oil $90 \%$ for surface temperature $477 \mathrm{~K}$ are shown by crosses. 


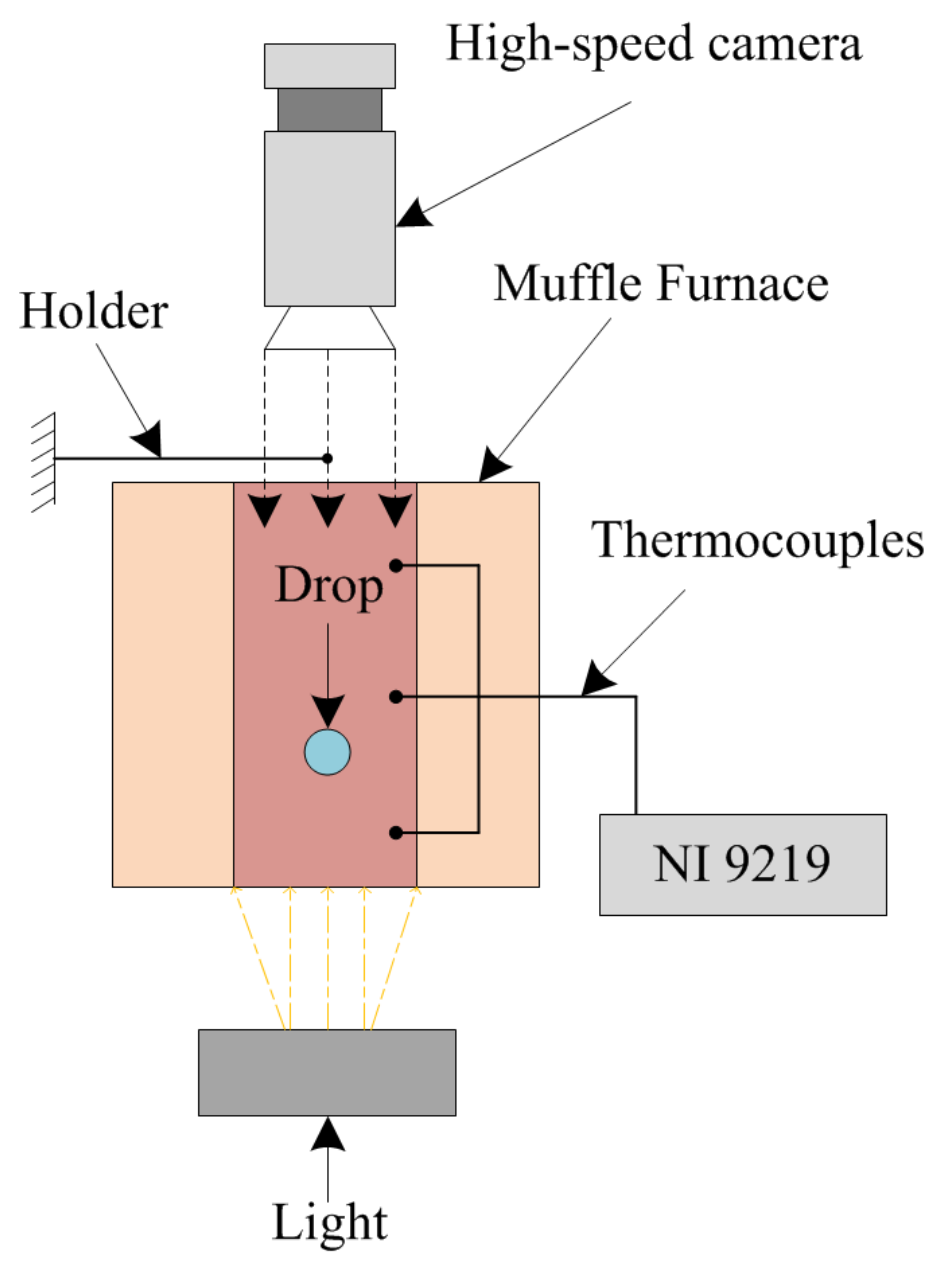

Fig. 1 

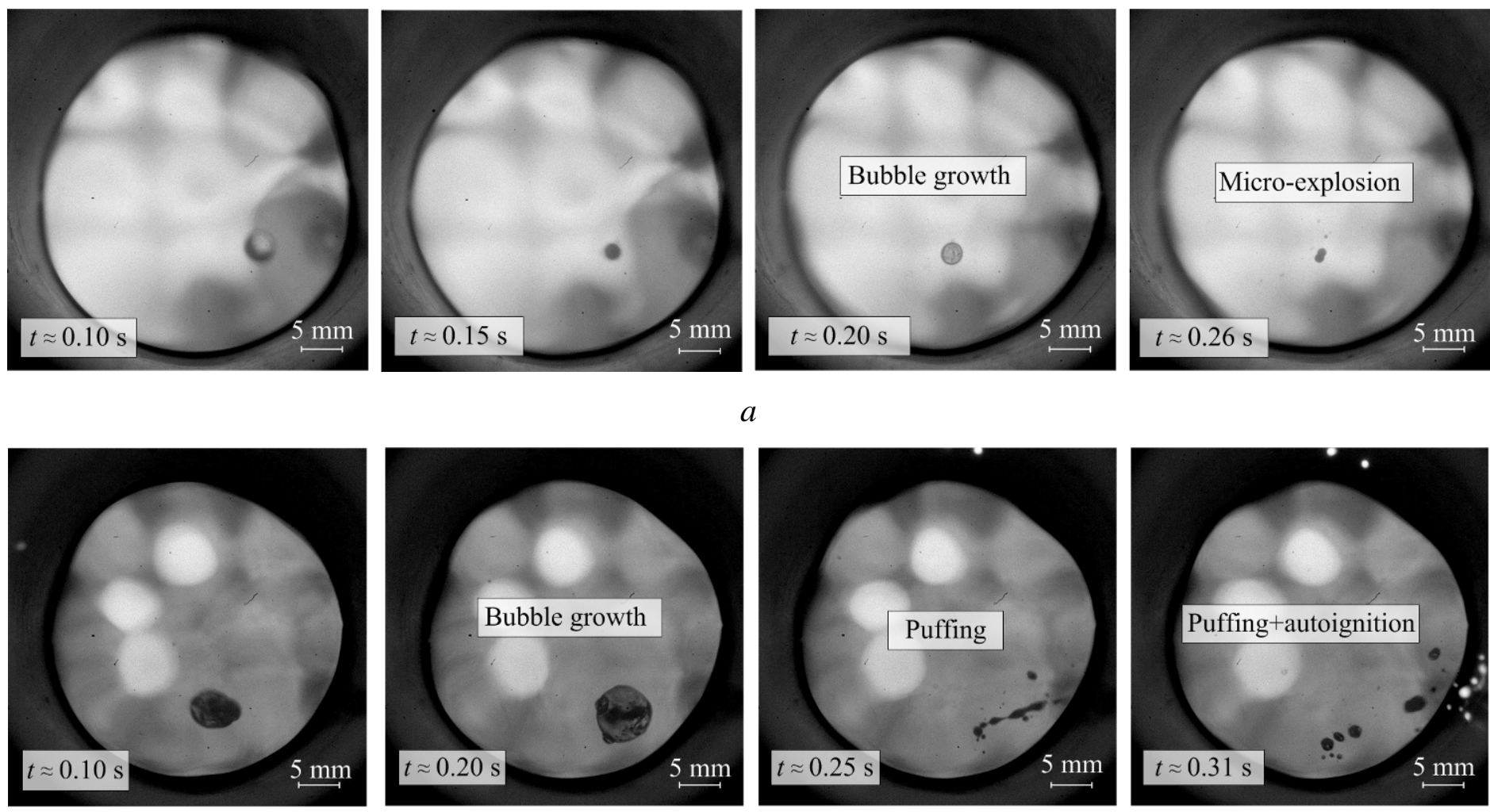

b

Fig. 2 

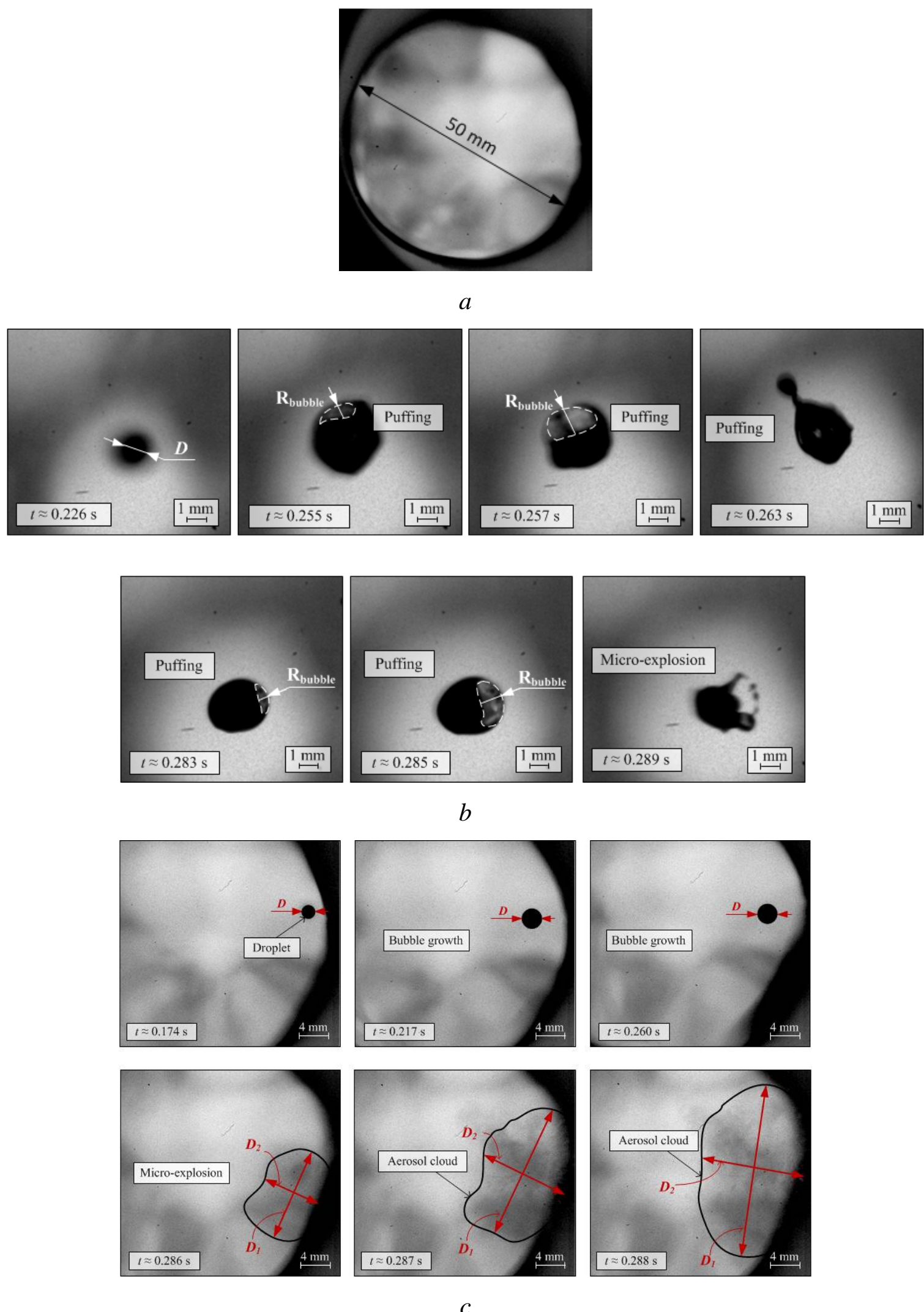

Fig. 3 


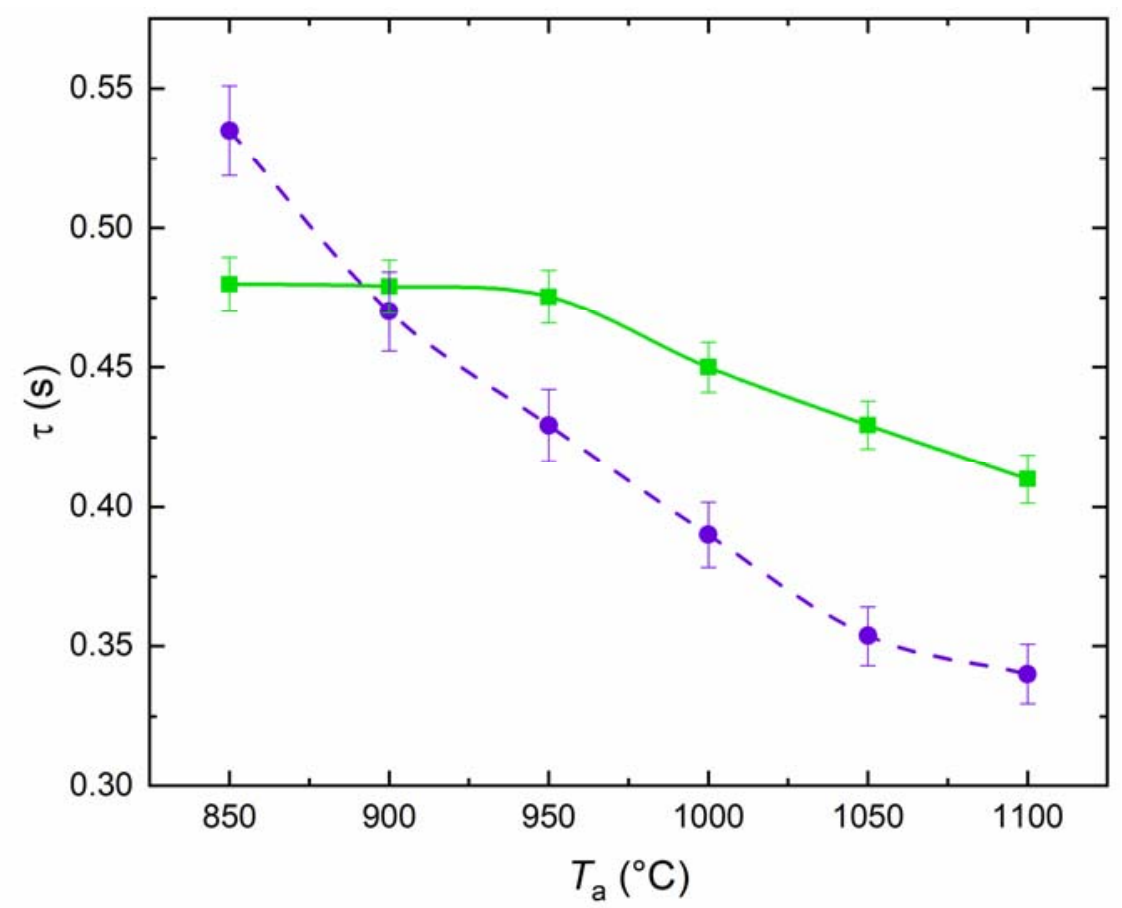

Fig. 4

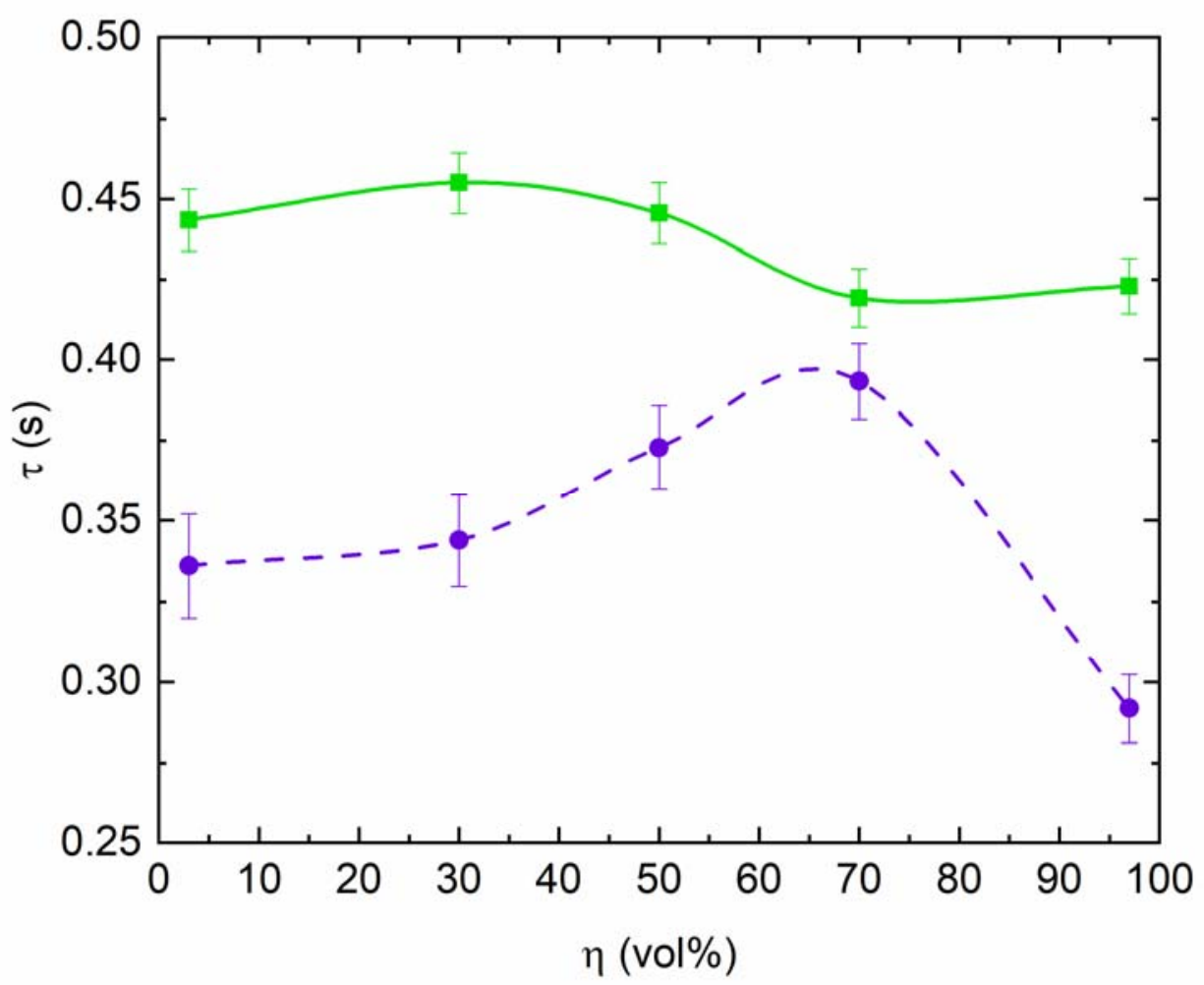

Fig. 5 


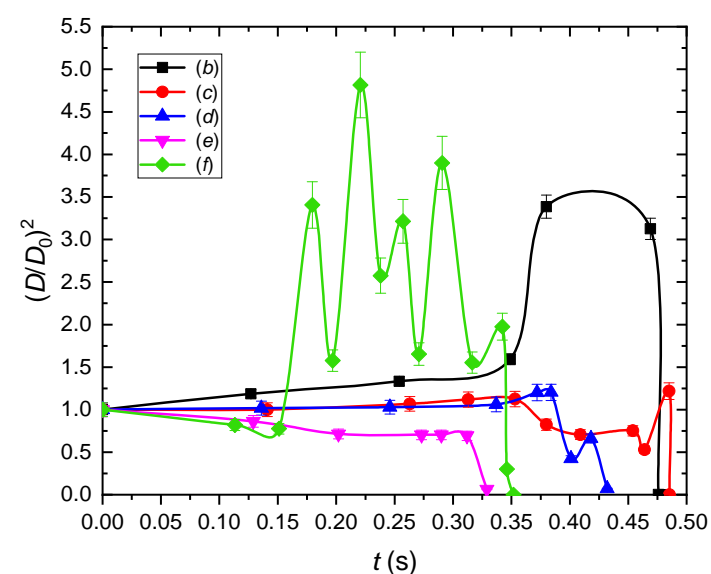

$a$

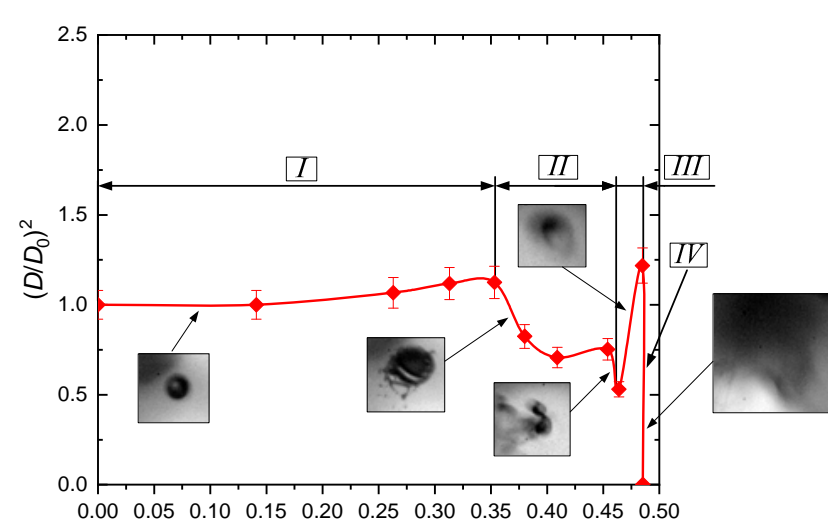

$t(\mathrm{~s})$

C

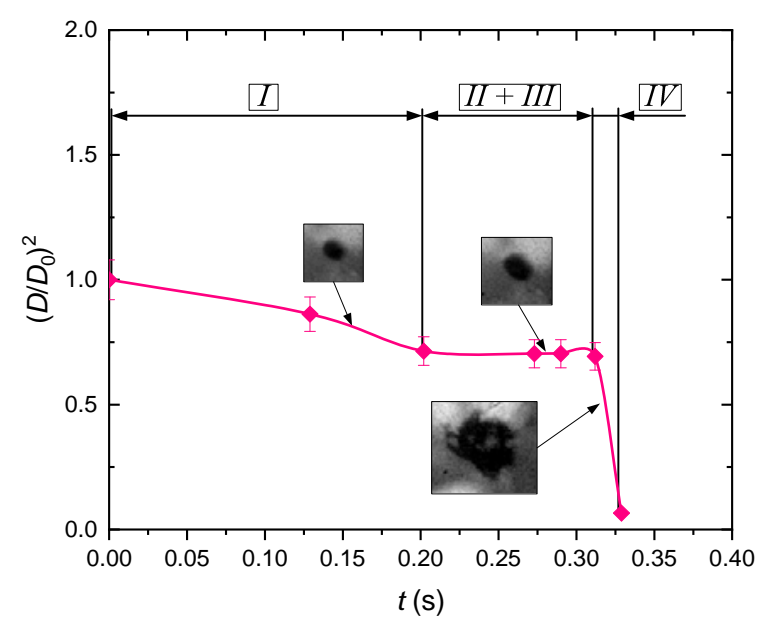

$e$

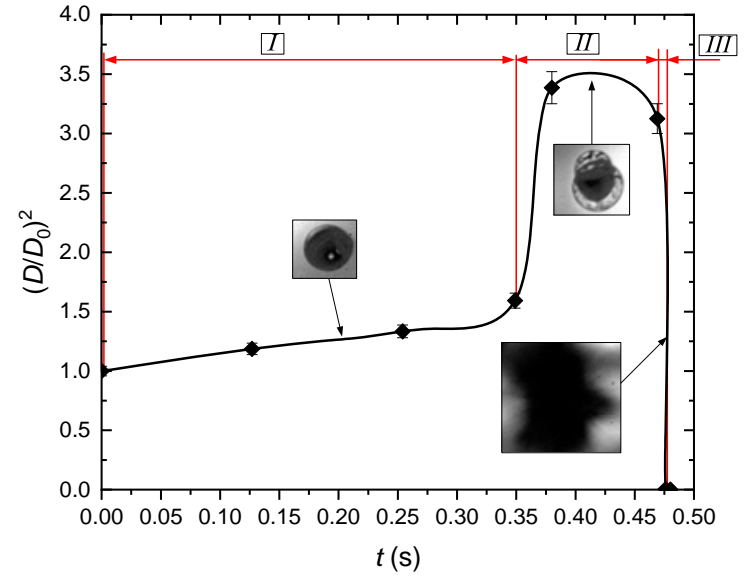

b

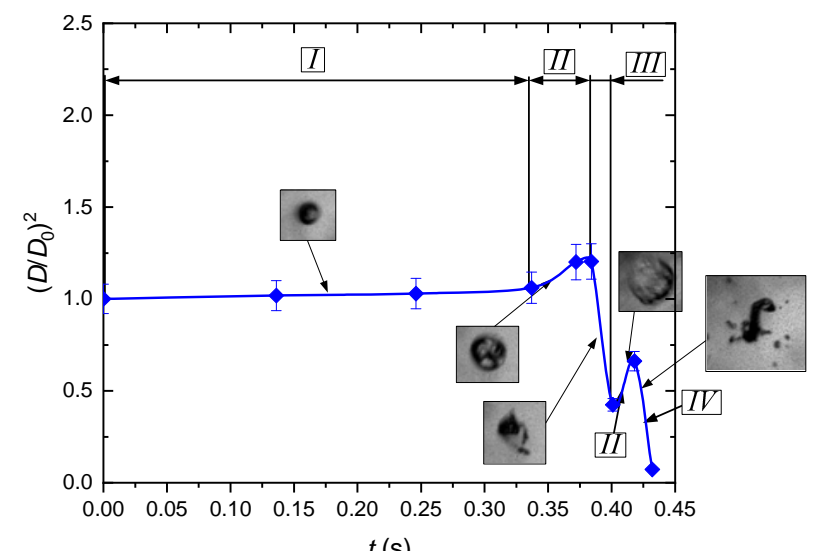

$d$

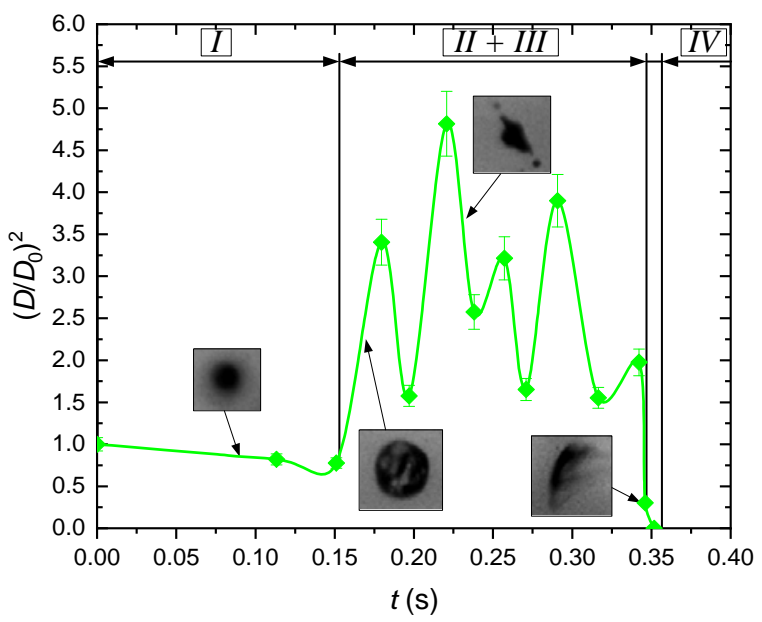

f

Fig. 6 

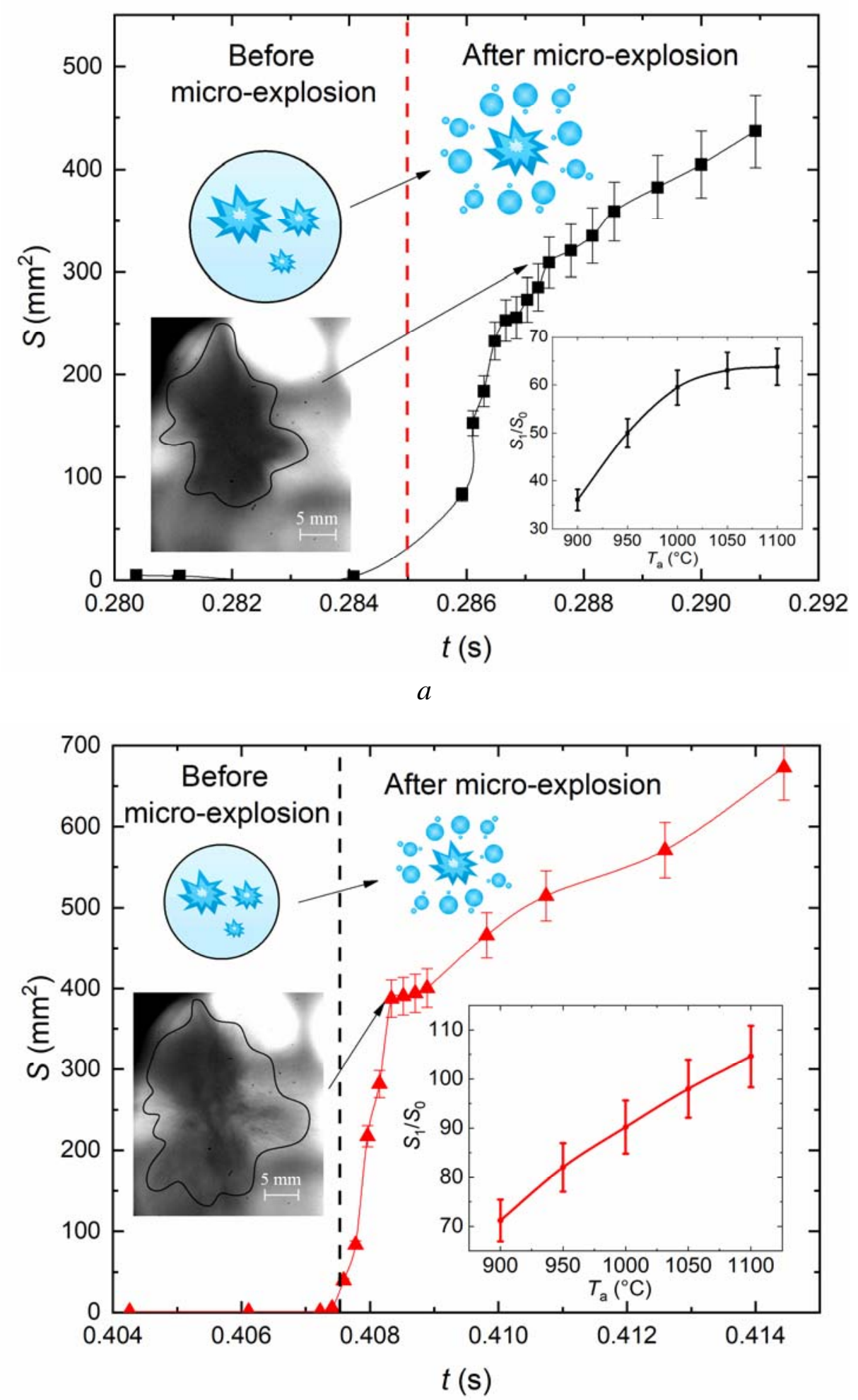

b

Fig. 7 


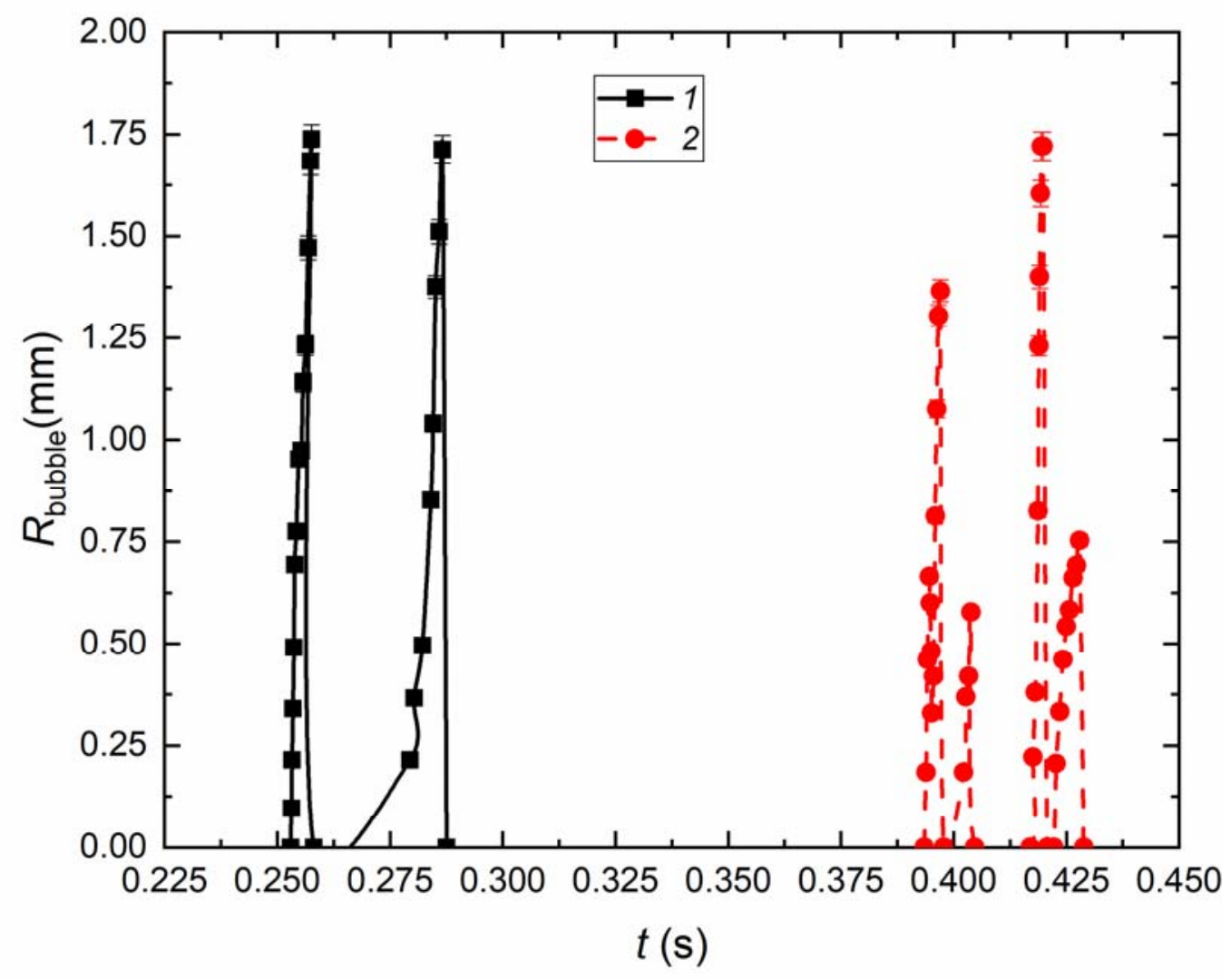

Fig. 8

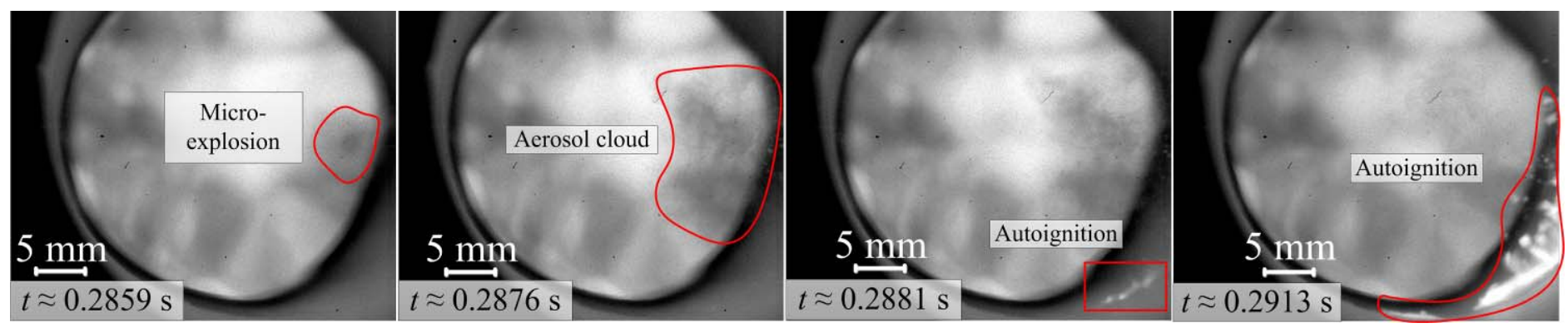

Fig. 9 

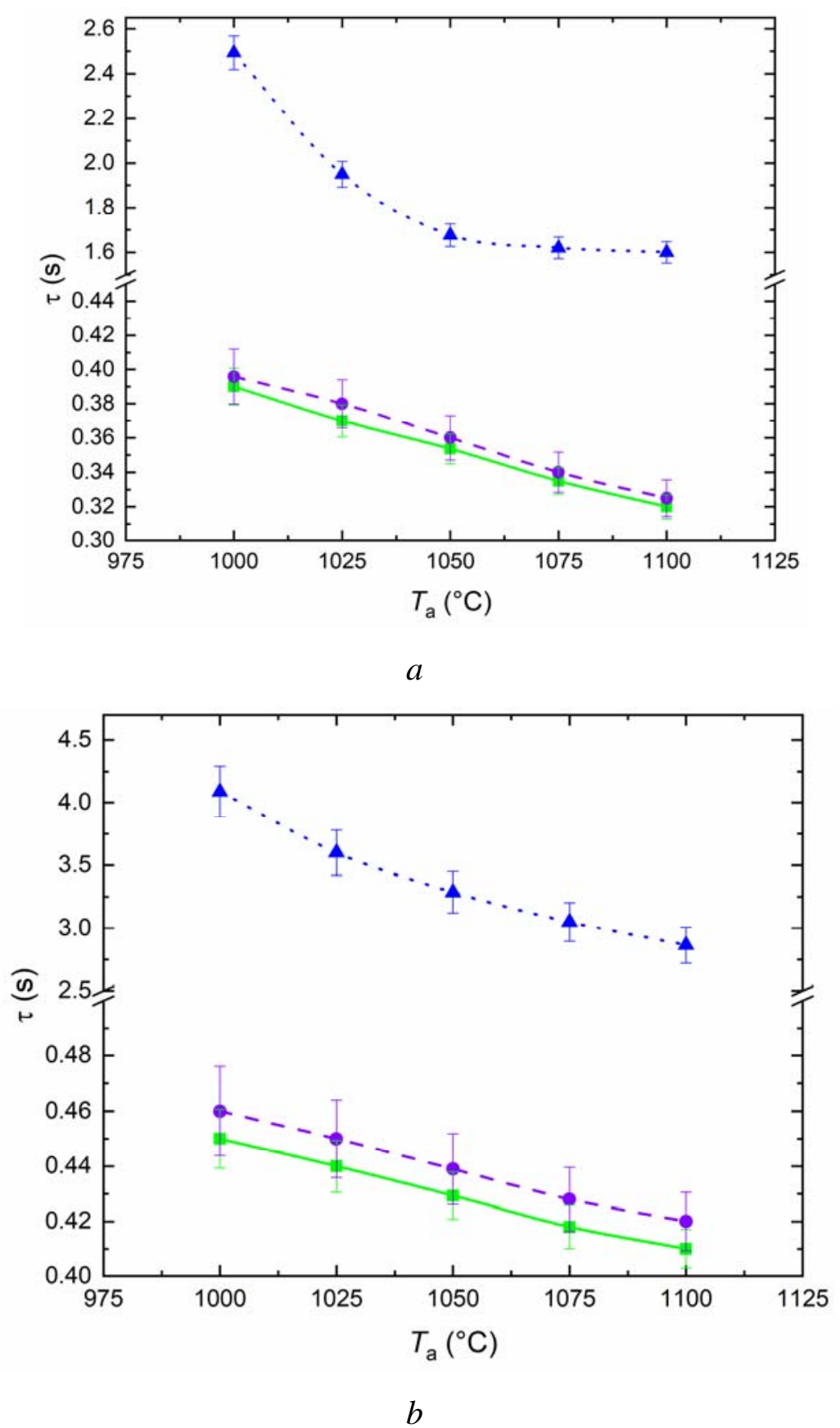

Fig. 10 


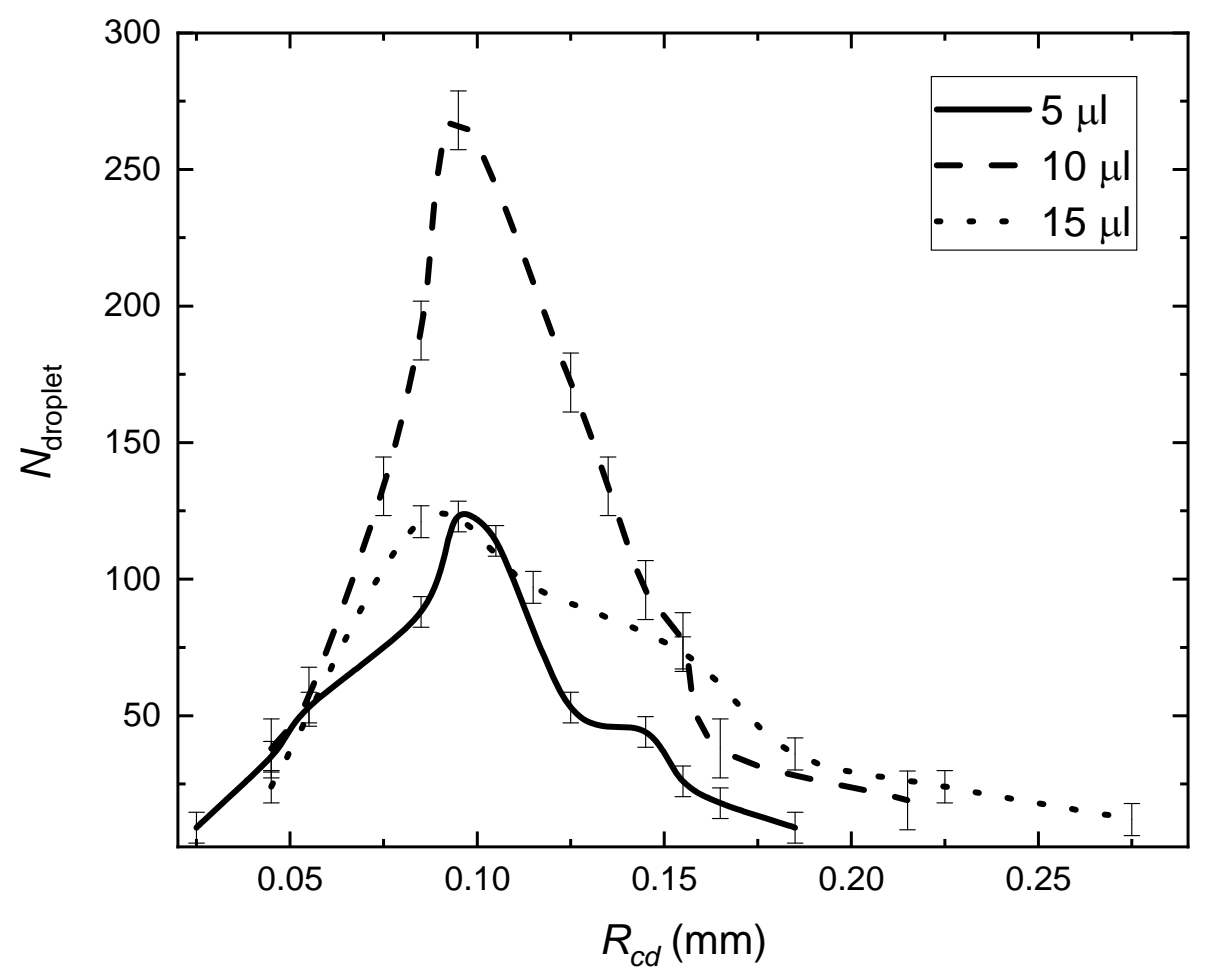

Fig. 11 


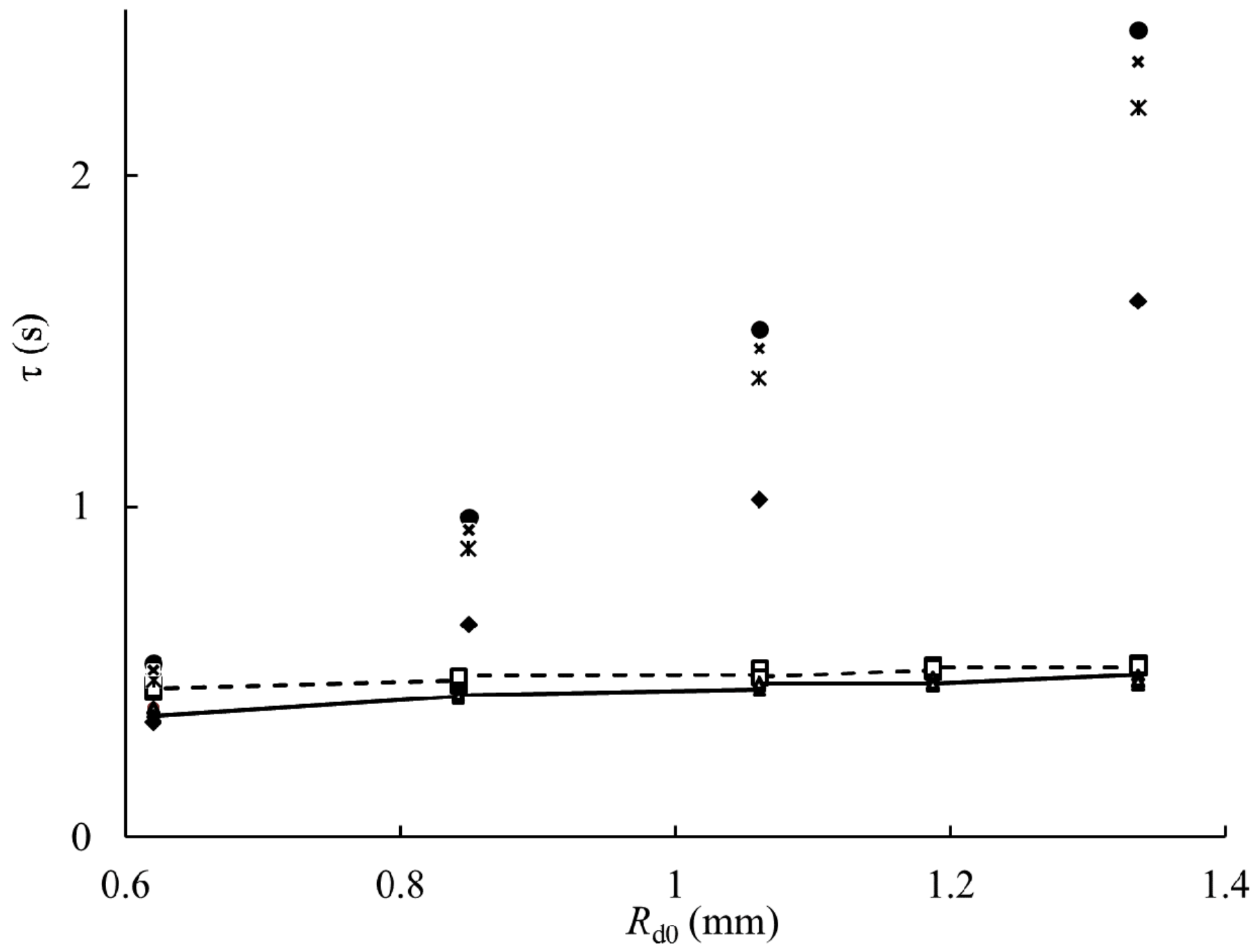

Fig. 12 